REVISTA CHILENA DE LITERATURA

Diciembre 2014, Número 88, 63-76

\title{
A MÍSTICA EM AGUSTINA BESSA-LUÍS E CLARICE LISPECTOR
}

\author{
Maria Lúcia Dal Farra \\ Conselho Nacional de Desenvolvimento Científico e Tecnológico \\ mldalfarra@gmail.com
}

RESUMEN / RESUMO / ABSTRACT

Se trata de examinar la aproximación a la condición de mujer en dos escritoras de la misma generación: la brasileña Clarice Lispector (nacida en 1920) y la portuguesa Agustina BessaLuís (nacida en 1922). Son objeto de estudio las respectivas novelas que publican en un mismo período: La sibila, de Agustina, es de 1954, y La pasión según G.H., de Clarice, es de 1964. A través de estrategias narrativas y discursivas muy diversas, cada obra se vale de la temática de la naturaleza mística (que envuelve lo femenino) para solapar las bases culturales, estructurales e ideológicas de donde parten, exponiendo la inadaptación al mundo estabilizado y demoliendo el código novelesco.

PALABRAS CLAVE: misticismo, mujeres, novela, desasosiego.

Trata-se de examinar a abordagem da condição concernente à mulher em duas escritoras da mesma geração: a brasileira Clarice Lispector (nascida em 1920) e a portuguesa Agustina Bessa-Luís (nascida em 1922). São objeto do estudo os respectivos romances que publicam numa mesma faixa temporal: A sibila, de Agustina, é de 1954, e A paixão segundo G.H., de Clarice, é de 1964. Cada obra, através de estratégicas narrativas e discursivas muito diversas, se vale da temática da natureza mística (que envolve o feminino) para solapar as bases culturais, estruturais e ideológicas de onde partem, expondo a inadaptação ao mundo estabilizado e desmanchando o código romanesco.

PALAVRAS-CHAVE: misticismo, mulheres, romance, desassossego.

This article examines how two female writers from the same generation approach the feminine condition: the Brazilian Clarice Lispector (born in 1920) and the Portuguese Agustina BessaLuis (born in 1922). The analysis focuses on two of their novels published in the same time 
period: La Sibila, by Agustina, was written in 1954, and La Pasión Según G.H., by Clarice, was written in 1964. Through diverse narrative and discursive strategies, these two works explore the mystical nature (which encompasses the feminine condition) in order to address the cultural, structural and ideological grounds from where they are based. By doing so, they expose the inability to adapt to the idea of a stable world and undermine the code of the novelistic genre.

KEYWORDS: mysticism, women, novel, discontent.

Para Gilda Oswaldo Cruz: a concertista, a romancista, a ensaísta e a amiga

Uma das mais inquietantes experiências de leitura ficcional é a d'A paixão segundo G.H. de Clarice Lispector. O livro é verdadeiramente insuportável, no sentido de que estabelece um pacto penoso com o leitor. É-lhe solicitado que dê a sua mão à narradora (para apoiá-la, para dar-lhe sustentação) a fim de que ela atravesse, já então por meio do verbo e do discurso, o inferno (e a glória) que conheceu -para que comece um novo talento de existir. Amparála nessa contingência tão radical é muito desconfortante, e o leitor não pode nem mesmo se relaxar nessa travessia de inesperados e desculturalizados incidentes. Deveras: ao iniciar o romance, ele ingressa numa temperatura máxima que vai conservá-lo, sem descanso, no mesmo grau de ansiedade até o final. Em regime de máxima intensidade, o persistente clímax não oscila e vai tensionando a linha narrativa quase a ponto de esgarçá-la. Conhece, então, o leitor de Clarice Lispector que este sim é o verdadeiro livro do desassossego.

Diversa receptividade terá ele aquando da leitura de Agustina Bessa-Luís. O romance $A$ sibila, ao contrário, permite que ele se instale no bembom, no aconchego de uma linguagem (digamos) materna ${ }^{1}$, que parece agasalhá-lo e ritmá-lo na narração de histórias pitorescas do povo, que avivam costumes antigos, crenças, expressões e linguajar populares, para a transmissão de uma herança cultural, no colo da qual ele se sente seguro e protegido. Mas

1 A expressão é de Silvina Rodrigues Lopes (1989), que a utiliza para designar a linguagem da consolidação e do hábito que Agustina aparentemente professa, com o intuito de abrir nela um movimento de desterritorialização -o que revela, afinal, a linguagem de Agustina como (sou eu que concluo) uma linguagem "madrasta". 
nem tudo transcorre em berço esplêndido. Um ou outro tropeço parecerá se dever, no entanto, a um vocabulário castiço do Norte de Portugal, de onde emergem a autora e sua sabedoria ancestral, e, talvez, à sinuosidade das orações muito alongadas. Através de encaixes subordinados e coordenados, estas proliferam a narrativa e a irradiam por diferentes tempos e paragens numa escrita em "tapeçaria aberta", no dizer de Eduardo Lourenço, num fluxo contínuo do pensamento, à maneira da durée bergsoniana, como a vê Maria Alzira Barahona (1968) ${ }^{2}$. Agustina não tem compromisso algum com o tempo, que usa como mola para saltar e retornar de uma para diversas épocas ao longo de mais de cem anos, numa especulação constante que vai varando esse tecido e se abrindo em múltiplas hipóteses.

O estilo de Clarice é já bem outro: frases curtas, fragmentadas, cortantes, discurso que avança em caleidoscópio semântico e que se esforça por traduzir a si mesmo continuamente, valendo-se de fecundos intervalos de sentido ou de meandros de significados cada vez mais disparatados ou desconcertantes. O que causa ao enredo uma estranheza ambulante já que, parecendo não gerar novos episódios, a trama não se encontra de fato emperrada, mas antes fincada numa expansão que se aprofunda, em lugar de se espalhar, condensação que a vai fertilizando com ressonâncias imprevistas. Porque a acústica de sensações machuca e implode, com novas nervuras, a face do que se diz, transmutando-a em outra e outra superfície, em moto contínuo.

No caso do romance a que me refiro, a ação é escassa; e o tempo linear, embora marcado por rigorosa e precisa anotação de horas, é, entretanto, quase nulo ${ }^{3}$. E isso porque o presente do discurso, que é o tempo da escrita, se realiza no denso testemunho do que ontem se passou, a fim de que a narradora possa seguir imediatamente em frente, visto que luta, a partir de então, contra a esperança e o adiamento que esta implica.

Já a efabulação de Agustina é, em tudo, diversa. Abundante, ela transborda, no sentido de que se prolifera em ações, comentários e aforismos, numa espécie

Sobre o tempo em Agustina, ver também Magalhães (1987).

Sobretudo uma das onze categorias agenciadas por Clarice sobre a obra romanesca tradicional, e indicadas por Lúcia Helena (1997), parece referendar perfeitamente este romance. Visto que ele apossa-se "livremente de uma série de modalidades de textualização, de fragmentos e 'ruínas' culturais de referência histórica e bíblica, com que elabora uma nova geografia da imaginação e do espírito através da intertextualização deste material" (107). 
de didascália que aponta para onde olhar o leitor e no que reparar ${ }^{4}$. Repleto de pequenos detalhes e afeito a minúcias que, acompanhando a fala de um personagem, podem dilatar-se infinitamente, o entrecho se permite também desviar-se na direção do mais ínfimo componente. E vai, assim, povoando alentados parágrafos, numa profusão de orações incrustadas umas nas outras ${ }^{5}$.

Uma personagem, por exemplo, ao se despedir de uma segunda, se prepara para dialogar com aquela que está a seu lado, e que se acha entretida numa outra função: no caso, cear. Ora, a narradora de Agustina segue não só essa pessoa ao lado, como vai mais além, detendo-se nos motivos que ilustram a porcelana que ela segura na mão, a ponto de também dar vida à cena estampada na tigela do caldo que ela toma. Assim temos que, "Quando ele partiu, ela meneou várias vezes a cabeça, calada; depois, com o seu trejeito de mão sacudido e quase irônico, que ela empregava por acirrado hábito e que lhe servia para testemunhar desdém e, sobretudo, esconder o seu pensamento real, dirigiu-se à moça, que ceava, cabisbaixa e esmoendo boroa na malga, em cujo bojo uma espécie de S. Tiago com tiara de Pope parecia prestes a lançar-se num galope glorioso abaixo do seu pedestal" (Bessa-Luís 138).

Já Clarice pratica muitas vezes uma linguagem que passa rimbaudianamente por "un long, immense et raisonné dérèglement de tous les sens" o que obriga o leitor a se apoiar sobre um território movente e minado ${ }^{6}$. No $22^{\circ}$ segmento do romance, por exemplo, G.H., numa das múltiplas alegorias, rouba o cavalo de caça do Rei do sabá, visto que procura "a danação como uma alegria". E durante todo o tempo, na noite enquanto dorme, ao entardecer ou de madrugada, o ginete respira chamando-a, porque o trote continua nela. $\mathrm{O}$ cavalo conduz seu pensamento, se é pensamento, ela questiona,

esta hora entre latidos. Os cães latem, começo a entristecer porque sei, com o olho já resplandecendo, que irei. Quando de noite ele me chama para o inferno, eu vou [...] Correm atrás de nós cinqüenta e três flautas. À nossa frente uma clarineta nos alumia. E nada mais me

4 Inês Pedrosa repara acertadamente que "os limites" é que apuram em Agustina "a consciência do infinito" (20 mulheres 67).

5 Em outro texto, Inês refere o "inacabamento voluntariamente esperançoso nos romances de Agustina" (A orquestra 15).

As indicações sobre Rimbaud dizem respeito à celebre carta dirigida por ele a Paul Démeny, conhecida como Lettre du Voyant, e que data de 15 de maio de 1871. E também se espraiam pela sua obra poética, notadamente por Une saison en enfer. 
é dado saber. De madrugada eu nos verei exaustos junto ao regato, sem saber que crimes cometemos até chegar a madrugada ${ }^{7}$. Na minha boca e nas suas patas a marca do sangue. O que imolamos? De madrugada estarei de pé ao lado do ginete mudo, com os primeiros sinos de uma Igreja escorrendo pelo regato, com o resto das flautas ainda escorrendo dos cabelos" (Lispector 128).

Não é preciso frisar: os dois exemplos que venho de citar evidenciam que cada autora solicita do seu leitor um comportamento específico. Há, de um lado, a escritora brasileira, que age quase perversamente, partilhando com ele um acontecimento impossível e dilacerante para a comunicação do qual ela precisa fabricar uma linguagem; e há, de outro, a escritora portuguesa que o traz para o seu regaço e que o vai acalentando com histórias tão saborosas quanto arrebatadoras.

Mas diante de tal desigualdade de tratamento, com razão o leitor se perguntará o que leva a serem tão distintas duas romancistas contemporâneas, nascidas quase no mesmo ano (Clarice é de $1920^{8}$, Agustina é de 1922), criadas na província (Clarice em Alagoas, no Nordeste Brasileiro; Agustina em Vila Meã, no entre Douro-e-Minho, Norte Português), adaptadas depois em grandes capitais (Clarice no Rio de Janeiro; Agustina em Coimbra e no Porto), escrevendo seus romances na mesma década (A sibila é de 1954; A paixão segundo $G$. $H$. é de 1964) e que usam a mesma língua para se comunicarem. Por que deve ele se acautelar com Clarice e se entregar à Agustina? Por que fica apreensivo com uma enquanto à outra se rende?

A pergunta é inútil pois que, ao fim e ao cabo, ele convirá que tanto uma quanto outra fazem um mesmíssimo trabalho de sapa, solapando as bases culturais, estruturais e ideológicas de onde partem - este o grande elo a unilas afinal. Clarice trabalha em aparência de maneira pouco misericordiosa

7 Alfredo Bosi, em História Concisa da Literatura Brasileira, anota que Clarice articula a experiência metafísica por que passa em A paixão segundo G.H. "valendo-se do verbo 'ser' e de construções sintáticas anômalas que obrigam o leitor a repensar as relações convencionais praticadas pela sua própria linguagem" (Bosi 425). Este é bem o caso da estranheza que causa ao leitor o "eu nos verei exaustos", constante do trecho citado.

Nádia Battella Gotlib, reconhecidamente a mais importante estudiosa da vida de Clarice, dedicada ensaísta de sua obra, depois de contracenar os dados controversos acerca da data de nascimento da escritora (discordância, aliás, fomentada pela própria Clarice), conclui que quando ela chegou ao Brasil, desembarcando no colo de seus pais em Maceió, em fevereiro de 1921, tinha 2 meses (Gotlib 63). 
e direta, enquanto Agustina tem um modo mais matreiro de seduzir o leitor, desenvolvendo "uma sutil insídia da linguagem". Agustina desmonta, num "hibridismo suspeito", os universos fechados de que trata, "na tentativa de desviar a verdade dos arquivos para o errante da verdade", como percebe Silvina Rodrigues Lopes (A alegria 16).

E o nosso leitor concluirá que os dois procedimentos tão diversos não passam de simples estratégias de persuasão... para que as matérias de que elas se ocupam possam atingir, com eficácia, esse interlocutor. Vejamos.

$O$ feixe de motivos que anima tanto um quanto outro romance parece ser semelhante. Observo que em ambos topamos com uma temática de natureza mística envolvendo a esfera do feminino.

No caso de Clarice, G.H. terá um momento de revelação do que é a sua vida bem constituída de escultora burguesa (e dos impasses que a cercam), quando penetra no insuspeitável universo do outro ${ }^{9}$. Ou seja: quando, inopinadamente, ingressa na existência que se desenvolvera na surdina, paralelamente à sua, debaixo do seu teto, no quarto agora vazio de Janair, a ex-empregada da cobertura do prédio de classe média alta carioca, nos píncaros da qual o romance transcorre ${ }^{10}$.

O relevo geográfico não é gratuito, já que esse primeiro espanto, que ilumina G.H. a si mesma a partir de outra perspectiva, será o trampolim inicial para o mergulho nas profundezas do seu ser, nas raízes da existência que compartilha com toda a matéria. E é nesse instante que começa, também rimbaudianamente, a sua "saison en enfer".

Porque, ultrapassando esse estágio inaugural de um autoconhecimento apenas psicológico, G.H. será arremessada a uma experiência mística de descida ao caos primordial, numa desintegração da sua identidade, numa morte iniciática que, todavia, a revivificará e a situará em harmonia com a Natureza, com o Cosmos, com Deus. Dá-se, então, simbolicamente, a reintegração dela ao estado originário do Homem, e o conhecimento revelado é de que tudo o que tem não é seu - ela mesma pertença do desconhecido. Ao final dessa operação místico-esotérica, G.H. encontrará em si “a mulher de

9 Este "outro" é pronunciadamente o "diferente" de G.H. - Janair é a "estrangeira": negra, subtraída, muito bela (tem traços e postura de "rainha africana", como só agora nota G.H.), representante da favela que, de cima, da sua cobertura, G.H. vislumbra em baixo. De resto, Janair é "achatada como um baixo-relevo preso a uma tábua" (Lispector 40).

10 É bom de notar que "Janair" é quase um anagrama de "rainha"... 
todas as mulheres" (Lispector 174): eis como, então, um tema se enrosca no outro; eis como a mística, em Clarice, desemboca no feminino ${ }^{11}$.

Mas tal ritual só é processado mercê da participação de um ser primitivo, testemunha do imensurável tempo: a barata ${ }^{12}$. É este inseto que empiricamente G.H. se obriga a provar, numa comunhão difusa entre o sabath e a missa negra $^{13}$, num ritual que desafia a náusea e a nojo. Por meio dessa recusa à aculturação, ela ingressa, por fim, na revisão radical de tudo o que compõe o nosso mundo civilizado: o Amor, o Tempo, a Verdade, a Maternidade, a Dor, Deus - a Linguagem ${ }^{14}$. Sim, porque se tal penoso processo só existe à medida que é pronunciado, o nomear tem de implicar uma alquimia do verbo, já que para conhecer algo tão colado à coisa, a designação torna-se impedimento, distanciando o contacto direto com a ela ${ }^{15}$.

11 Raimunda Bedasee, que estuda a Violência e ideologia feminista na obra de Clarice Lispector (1999), conclui a respeito deste romance que Clarice representa um "modelo extremamente positivo da, e para, a mulher contemporânea". Tal modelo que, segundo ela, não incorpora estereótipos femininos e assume pulsões ditas masculinas, como a violência, ou como a independência, "está de acordo com o desenho feito por Janair, onde são representados um homem e uma mulher, o que significa 'a falta de lugar' atribuída a G.H. tanto sexualmente quanto na sociedade, por exercer a profissão de escultora e pela independência que possui - 0 que faz com que G.H. não pertença a lugar algum. Em outras palavras, G.H. reúne características da androginia" (106). E a androginia, como a concebe Jacques Vidal, significa, afinal, que "l'entièreté de la condition humaine est masculine et feminine" (Vidal 371).

12 Benedito Nunes comenta que o aparecimento da barata vem consumar o processo subterrâneo e fatal da desagregação de G.H. que já se iniciara quando sua vida começara a ser esvaziada da sua personalidade ao entrar no quarto de Janair, onde lhe aparecem os contrastes inconciliáveis da existência (Nunes 1973).

13 Cf. o inspirado texto de Berta Waldman.

14 Alfredo Bosi, num dos traços precisos com que revela os autores estudados na sua História Concisa da Literatura Brasileira, considera esta obra um "romance de educação existencial", e que o monólogo de G.H. decreta "o fim dos recursos habituais do romance psicológico". Por isso mesmo apreende no enfrentamento da narradora com a barata um "salto do psicológico para o metafísico". E acrescenta, citando Lévy-Bruhl, que "a diferença entre a mente primitiva e a civilizada" se dá em "termos de participação", de "integração dos pólos", para a primeira, e de "distância" para a segunda (Bosi 424-425).

15 Vilma Arêas indica que o "reconhecimento, uma vez assumido, impede a aventura e impele ao fabrico de uma cartilha que reinstaure a harmonia quebrada pelo excesso, ultrapassagem da medida humana" - provável caminho que Clarice buscará em Uma aprendizagem ou $O$ livro dos prazeres, onde "a comunhão agora é feita através do corpo amoroso, numa longa e minuciosa cerimônia de iniciação, evitando-se o abismo que G.H. não recusou mas que terminou numa instrução" (Arêas 49). 
E é por essa razão que o romance se perfaz como um obsediante tateio da linguagem ${ }^{16}$. É preciso reinventá-la, vergá-la para que ela dê conta dessa evidência, de modo a que possa transmitir tal absoluto, esse apogeu de ignorância que consiste no nada, no neutro, no caos, no vazio, no opaco, na mudez, no inexpressivo, no inumano - na falência de todos os valores da estética, da ética e da metafísica ${ }^{17}$. De modo que a "paixão" constante no título da obra, mostrando-se ao longo da narrativa uma experiência mística, acaba por se transmutar, em Clarice, numa operação ontológica ${ }^{18}$. E a maneira de comunicação empregada por G.H. não pode ser senão a de uma "linguagem sonâmbula", de uma espécie de tosca e impossível tradução de sinais, de uma linguagem de toques telegráficos (telepáticos?), de algo como uma transcrição fonética, um grafismo - um murmúrio. De modo que ela só pode nomear negando, exercitando obsessivamente a contradição e o oxímoro, que está na base dessa linguagem ${ }^{19}$, visto que descobre esta pequena coisa: "falar é mudo" 20.

Em Agustina, é como um dom inato, uma predestinação, revelada sobretudo após uma morosa doença adolescente de Quina, senhora da Casa da Vessada ${ }^{21}$, que a qualidade de conselheira, de força espiritual ligada ao sobrenatural nela se manifesta. Mas a floração dessa predisposição de

16 Em “Clarice Lispector: mulher macho, sim senhor!”, Fátima da Silva salienta que, de uma maneira geral, os personagens de Clarice não só questionam a linguagem mas refletem sobre $o$ ato criador.

17 Carlos Mendes de Sousa esclarece que o "neutro, o insosso equivaleriam àquilo que está próximo de Deus na tradição mística" (A relação 171). Ver também deste autor o recente e alentado volume publicado no Brasil: Clarice Lispector. Figuras de escrita (2011).

18 Cf. Olga de Sá (2004).

19 Na análise deste romance, Benjamin Moser (2009) conclui que o resultado obtido por Clarice "que talvez possa ser chamado de espinosismo místico ou ateísmo religioso, é o seu mais rico paradoxo até então" (Moser 38).

20 Cf. Yudith Rosenbaum (2004). Talvez o incômodo e torturante comportamento de leitura a que tenho referido se deva ao fato de que G.H., segundo Rosenbaum, "ao abrir-se para o ilimitado, distancia-se do mundo construído e partilha da lógica dos paradoxos, que é na verdade o campo do Real (como quer Lacan), do impossível de ser figurado. Ela se aproxima perigosamente da experiência psicótica, que seria a irrupção crua do Real sem a rede simbólica que o sustenta; é habitar uma trama sem contornos, sem limites, onde a linguagem compartilhada não alcança." (Rosenbaum 267, o grifo é meu).

21 Catherine Dumas afirma que em A sibila "l'esprit des lieux se situe dans cet espace unissant la Maison et la terre possédée, cette 'quinta' animée par l'esprit féminin allié à l'eau." (Dumas 65). 
abertura para o impalpável e para o iluminado está associada, em Agustina, ao desenvolvimento de outras qualidades que, no romance, realizam o valor feminino. É como se cada mulher tivesse em si uma sibila dormente, que é preciso despertar.

A conversa atual entre os primos Germana e Bernardo, três anos após a morte de Quina, abre e fecha, como uma moldura, o romance de Agustina. E a narrativa vai se ocupar, saltitantemente, da geração feminina da Casa da Vessada, onde o casal se encontra, propriedade atual de Germa - de todos da Casa, a única descendente ${ }^{22}$. Germa guarda etimologicamente no seu nome o germe dessa Casa de mulheres, e, por um golpe do acaso, também o sobrenome da matriarca, a sua avó ${ }^{23}$. Se, como diz a narradora, os nomes das casas transmitem-se pelos filhos varões e os costumes são herança das mulheres, aqui, ambas as prerrogativas serão exercidas pela mulher. Germa, sobrinha e espelho de Quina, parece propagar e levar para adiante, ao final do romance, a aprendizagem acerca dessa força espiritual feminina que a tia, reedificando a Casa, em tempos afundada pelo desbragamento de pai e irmãos, concentrou. De maneira que o romance se encerra acenando para adiante, projetando-se através do lastro meritório que Germa extrai do retrospecto de mais de cem anos (que é o corpo do romance), e que tem início com as mulheres do tempo da sua bisavó.

Naquela época, era ainda vigente o anátema que recaía sobre os rebentosfêmeas. As filhas eram desprezadas pelo pai e criadas em separado dos membros masculinos da família, nos casebres dos caseiros - esse o caso da mãe de Isidra. O casamento consistia então na união de dois patrimônios, de modo que quando a Casa desanda, tanto Quina quanto sua irmã Estina perdem seus pretendentes. Esse duro golpe repercutirá para sempre na vida de Quina, que escolhe o respeito em lugar do desejo, alçando-se, em seguida como

22 Vale lembrar que não há exatamente uma hierarquia de personagens. Agustina acompanha as ramificações entre elas (que pode ser de natureza muito diversa), segue essa imensa família, parentes, agregados, amigos, vizinhos, e vai criando o contexto onde Quina aparece, personagem que também não é a sua única ocupação narrativa. Por isso mesmo Inês Pedrosa se dá conta de que nos "romances de Agustina, precisamente porque movidos por um democrático sentido de composição ou justiça, dilui-se a noção de personagem secundária: todas as figuras têm o seu momento de intervenção essencial - é isso o que de imediato torna os seus livros sedutores e acessíveis a leitores intuitivos e não-iniciados" (A orquestra 15-16).

23 A idéia de Germa como germe também está em Monica Rector: “A sibila de Agustina Bessa-Luís" (s/f). 
cobiçado partido que, todavia, recusa quaisquer investidas, permanecendo solteira por decisão própria. Caso contrário é o de Estina: sua infeliz escolha há de comprometer os filhos, falecidos por maus tratos do pai, enquanto a filha enlouquece e morre.

Mulheres há, em contrapartida, que desandam sua vida apenas por prazer em desafiar o nome que trazem (o caso de Isidra) e outras, como a amortalhadeira Domingas, que providencia ela mesma a sua justiça, envenenando um a um os maridos e dando fim aos indesejados filhos. Mas aquelas que mais ojeriza causam a Quina são as da sociedade, as fidalgas, cuja intimidade ela conhece: segundo ela, parecem viver como numa cela de loucas, sem pudores, sem moral, sem leis.

À medida que Quina constrói sua independência econômica, entranhase mais nela a aversão aos homens que não ultrapassam a inferioridade que ela fora capaz de vencer. Às mulheres, de maneira geral, atribui-lhes uma "categoria deprimente", considerando que usam o amor com instinto de ganância, enquanto parasitas e não companheiras de seus homens, deplorandolhes a condição de "escravas regaladas" (Bessa-Luís 117). Por isso, o seu conselho a Germa não pode ser diferente: "Menina [...] não te cases nunca. É a maior desgraça que pode acontecer a uma mulher" (142).

Não por acaso, o lema de Germa será preferir o perigo embora o tema; odiar a dádiva embora a cobice; ter a consciência de que aceitar é ser vencida; e que a luta é um apelo constante, uma necessidade absurda e inapelável (147). Esta poderia ser também a divisa da própria Agustina que, segundo Silvina Rodrigues Lopes "pensa sem temor nem repouso no pensável e no impensável, arriscando saltar no escuro todos os muros até hoje estabelecidos" (Agustina 30).

Pois bem. O que importa considerar, em sintonia com o romance de Clarice, é que a perspectiva ideológica implícita no romance de Agustina indica que a aceitação da condição feminina é deplorável, sendo em contrapartida a insurreição da mulher, qualquer que seja ela, um valor poderoso e diferenciador. De todos os atributos que Germa retira de Quina, o mais proeminente é o de constatar que ela "acusava e defendia com o mesmo denodo de consciência", como se estivesse sempre do outro lado do muro, "fazendo saltos à vara por cima dele", por puro desafio (127-128). Afinal, a "contradição era o seu profundo conteúdo humano" (128). Era essa força de espírito o que fazia dela, um "ser trivial e sem gênio", "uma mulher vaidosa e fraca", com desejo de expansão e de público, carente de adulação e de admiração (134) - uma 
mística, uma sibila. E esse misticismo era humanista, sim, porque era uma revolta; era a rebelião audaciosa e admirável da sua ignorância.

É esse exemplo substancial de energias humanas que entre si se devoraram e se deram vida, que Germa reterá definitivamente de Quina. E, como a indicar sibilinamente em si mesma tal contradição, é no vai-e-vem da cadeira de balanço da tia (o seu trono de herdeira), num movimento de ser-e-não-ser muito próprio da contradição, que Germa chega a essas conclusões.

Quanto a mim, concluo, sempre provisoriamente que, seguindo de perto suas personagens, Agustina e Clarice também fazem finca-pé numa condição paradoxal de entremeio, num estado de periclitância, de estar à beira de, aplicando-se no desmanche do código romanesco, ostentando a inadaptação ao mundo estabilizado, quebrando a rotina literária. Não diversamente de Agustina, também há, em Clarice, um "triunfo da escrita, o assomar da desordem absoluta, de onde nasce a obra que guarda o segredo dos seus enigmas prodigalizando os vestígios que a eles conduzem"24.

Semelhante selo vigora nas personagens de ambas as escritoras, graças à fresta que nelas vislumbraram para expressarem os seus valores femininos. Não é à toa que criaram, cada qual no seu próprio registro, uma personagem mística, visto que "o misticismo tornou-se, na história do Ocidente, o único lugar onde às mulheres era permitida voz e agência públicas" (Irigaray, cit. em Ferreira 119).

Ora, a figura da sibila e de G.H. se manifestam no ponto de clivagem entre o rejeitado e o afirmado, lugar onde têm-se inscrito as mulheres dessa "comunidade infigurável" 25 . As "ilusas", as "beatas" e as "alumbradas" que, pelo menos desde o século XVI, têm representado, mercê do viés místico, um modelo feminino mais desenvolto (e que, por isso mesmo beira tanto à emancipação quanto à heresia) - são certamente as ancestrais destas místicas criadas por ambas ${ }^{26}$.

24 Cf. Silvina Rodrigues Lopes: "Sobre Agustina Bessa-Luís" (2003). Silvina está se referindo à Agustina e não à Clarice, coisa que eu faço.

${ }_{25}$ O conceito é de Teresa Joaquim, que o elucida em "A (im)possibilidade de ser filósofa" (2001), como ensina Ana Maria Ferreira, na obra citada, considerando que ele expressa mais plenamente a "invisibilidade das mulheres". Cf. também Teresa Joaquim: As causas das mulheres. A comunidade infigurável (2006).

26 Esclareço o significado de tais categorias através da citação direta de Ana Maria Ferreira. As "ilusas" compreendiam as "mulheres que viviam fora do controle da Igreja que não as reconhecia como dignas por lhes atribuir vícios não compatíveis com o espírito 
Esse espaço intervalar existente tanto em G.H. quanto em Quina, espaço que é trégua do sistema e empenho em ouvir as vozes interiores que delas irrompe, subverte a ordem simbólica e situa-as num patamar fora do controle social. Esse o "ponto exterior" onde elas se localizam em relação à vida; esse o "círculo" que constroem em torno de si e que ninguém pode transpor (como bem se dá conta Germa); esse o "absoluto" a que elas se dedicam (237).

Porque, em estado de êxtase, de transe, apartadas da restante Humanidade, deixando vazar seus sonhos, devaneios, visões, matéria móvel e pulsante em puro estado selvagem, o que elas elaboram é, antes de constituir-se construção social, uma incandescente e irradiante transgressão ${ }^{27}$.

\section{BIBLIOGRAFIA}

Arêas, Vilma. Clarice Lispector com a ponta dos dedos. São Paulo: Companhia das Letras, 2005. Barahona, Maria Alzira. "Agustina Bessa-Luís. Um tempo de derivação". Para um estudo da expressão do tempo no romance português. Lisboa: Publicações do Centro de Estudos Filológicos, 1968. 45-98.

Bedasee, Raimunda. Violência e ideologia feminista na obra de Clarice Lispector. Salvador: UBFA, 1999.

feminino-submisso da época. Eram prostitutas, viúvas sem recursos econômicos, órfãs ou mulheres abandonadas pelos maridos. Eram denominadas ilusas por iludirem os confessores a fim de terem acesso à confissão - o que não seria possível se o seu "estado" fosse reconhecido. Foram perseguidas pela Inquisição, embora não fossem consideras bruxas - se o fossem, só a fogueira lhes estaria destinada". As "beatas" eram "mulheres laicas, independentes da tutela masculina (viúvas, órfãs ou sem irmãos a quem por força haveriam de submeter-se), que reclamam o direito à espiritualidade e o seu lugar no processo de reforma da igreja católica. Impõem-se sem aval ou agrado da hierarquia masculina, como forma alternativa de ingressar na vida religiosa cujo nascimento ou falta de recursos econômicos lhes vedava a entrada no convento. Poderiam ser também monjas, com ou sem hábito, mas com ligações à comunidade, no que diferiam da Monja a quem o Concílio de Trento veio obrigar a clausura e transformar no símbolo de pureza e devoção, emblema de redenção da mulher/Eva aos olhos da Igreja Católica". As "alumbradas" eram conhecidas na Península Ibérica, nos séculos XVI e XVII, pela sua ligação com a Reforma e com os Luteranos. "Religiosos de devoção e conhecimento espiritual iluminado pelo santo sacramento do baptismo, a sua principal doutrina consistia em, por meio da oração, atingirem um estado tão perfeito que não lhes seria necessário abraçar ordens nem sacramentos. Foram, por tal heresia, ferozmente perseguidos pela Inquisição" (Ferreira 120-121).

27 Sigo, com Ana Maria Ferreira, parte de suas conclusões (140). 
Bessa-Luís, Agustina. A sibila. Lisboa: Guimarães Editores, 1970.

Bosi, Alfredo. História concisa da literatura brasileira. São Paulo: Cultrix, 1994.

Dumas, Catherine. "Les demeures d'Agustina". Correntes d'Escritas. Revista de Cultura Literária. Dossier Agustina Bessa-Luís (fev. 2010): 62-66.

Ferreira, Ana Maria. "O voo silencioso". Mulheres que escrevem. Mulheres que lêem. Repensar a literatura pelo gênero. Org. Chatarina Edfeldt e Anabela Galhardo Couto. Lisboa: 101 Noites, s/f. 117-141.

Gotlib, Nádia B. Clarice. Uma vida que se conta. São Paulo: Editora Ática, 1995.

Helena, Lúcia. Nem musa, nem medusa. Itinerários da escrita em Clarice Lispector. Niterói: Editora da UFF, 1997.

Irigaray, Luce. Speculum - de l'autre femme. Paris: Éditions Minuit, 1974.

Joaquim, Teresa. "A (im)possibilidade de ser filósofa”. Também há mulheres filósofas. Org. Luísa Ribeiro Ferreira. Lisboa: Caminho, 2001. 17-40.

As causas das mulheres. A comunidade infigurável. Lisboa: Libros Horizonte, 2006.

Lispector, Clarice. A paixão segundo G. H. Rio de Janeiro: Rocco, 2009.

Lopes, Silvina Rodrigues. A alegria da comunicação. Lisboa: IN/CM, 1989. Agustina Bessa-Luís. As hipóteses do romance. Lisboa: Asa, 1992.

"Sobre Agustina Bessa-Luís". Exercicios de aproximação. Lisboa: Edições Vendaval, 2003. 115-185.

Lourenço, Eduardo. "Des-concertante Agustina". O canto do signo. Existência e Literatura (1957-1993). Lisboa: Presença, 1994. 164-171.

Magalhães, Isabel Allegro de. “Agustina Bessa-Luís”. O tempo das mulheres. Lisboa: IN/ CM, 1987. 205-258.

Moser, Benjamin. Clarice. Trad. José Geraldo Couto. São Paulo: Cosac Naify, 2009.

Nunes, Benedito. Clarice Lispector. São Paulo: Edições Quíron, 1973.

Pedrosa, Inês. "A orquestra do imprevisível". Agustina. As chamas e as almas. Crónica do Cruzado Obs. As Fúrias. Lisboa: Guimarães Editores, 2007.

20 mulheres para o século XX. Lisboa: Publicações Dom Quixote, 2001.

Rector, Monica. “A sibila de Agustina Bessa-Luís”. Mulher, objeto e sujeito da Literatura Portuguesa. Porto: Universidade Fernando Pessoa, s/f. 207-214.

Rosenbaum, Yudith. "No território das pulsões". Cadernos de Literatura Brasileira. Clarice Lispector (2004): 264-276.

Sá, Olga de. "Uma metafísica da matéria ou uma poética do corpo". Cadernos de Literatura Brasileira. Clarice Lispector (2004): 280-301.

Silva, Fátima da. "Clarice Lispector: mulher macho, sim senhor!”. Mulheres que escrevem. Mulheres que lêem. Repensar a literatura pelo gênero. Org. Chatarina Edfeldt e Anabela Galhardo Couto. Lisboa: 101 Noites, s/f. 93-106.

Sousa, Carlos Mendes de. "A relação do nome". Cadernos de Literatura Brasileira. Clarice Lispector (2004): 14-192.

Clarice Lispector. Figuras da escrita. São Paulo: Instituto Moreira Salles, 2011. 
Vidal, Jacques. Symboles et religions. Paris: Julian Ries, 1990.

Waldman, Berta. "Uma cadeira e duas maçãs: presença judaica no texto clariciano". Cadernos de Literatura Brasileira. Clarice Lispector (2004): 241-260. 